\title{
Çocuk kırıklarının etiyolojisi ve epidemiyolojisi
}

\author{
Etiology and epidemiology of fractures in children
}

\author{
Osman Nuri Özyalvaç, Evren Akpınar
}

Metin Sabancı Baltalimanı Kemik Hastalıkları Eğitim ve Araştırma Hastanesi, İstanbul

\begin{abstract}
Çocuk kemikleri kalın periost yapısı ve düşük elastisite modülü sayesinde erişkine göre kırık oluşumuna karşı daha dayanıklı olsa da, çocuklarda kırıklar erişkine göre çok daha fazla görülmektedir. Bunun nedeni, çocukların daha fazla travmaya maruz kalmasıdır. Cinsiyet, yaş ve çeşitli çevresel etkenler çocuk kırıklarının etiyolojisi ve epidemiyolojisini önemli ölçüde etkilemektedir. Çocukların maruz kaldığı travmaların ve çocuk kırıklarının önüne geçebilmek için bu yaralanmaların etiyolojisi ve epidemiyolojisi hakkında bilgi sahibi olmak gerekmektedir.
\end{abstract}

Anahtar sözcükkler: çocukluk çağı kırıkları; çocukluk çağı kırıklarının etiyolojisi; çocukluk çağı kırıklarının epidemiyolojisi

\begin{abstract}
Although the bones of the children are more resistant to fracture than adults due to thick periosteum and low elasticity module, fractures are more common in children than in adults. This is because children are more exposed to trauma. Gender, age, and various environmental factors significantly affect the etiology and epidemiology of child fractures. To prevent the fractures that children are exposed to, it is necessary to have knowledge about the etiology and epidemiology of these injuries.
\end{abstract}

Key words: childhood fractures; etiology of childhood fractures; epidemiology of childhood fractures
Ç. ocukluk çağı kırıkları giderek artan sıklığı nedeniyle tüm dünyada önemli bir halk sağlığı sorunu haline gelmiştir. ${ }^{[1]}$ Çocuklarda kırık, erişkinlere göre yaklaşık iki kat daha fazla görülmekte ve 16 yaşına kadar her üç çocuktan birinin en az bir kez kırık ile karşılaştığı bilinmektedir. ${ }^{[2,3]}$ Çocuk kırıklarının insidansı, çocuğun yaşı ve cinsiyeti, mevsimsel ve sosyokültürel etmenler gibi birçok faktörden etkilenir.

\section{CINSIYET}

Yaşamın ilk iki yılında cinsiyetler arasında fark görülmezken iki yaş sonrası çocuklarda erkek cinsiyette önemli bir artış dikkat çeker. Landin ve ark.'nın çalışmalarına göre, 16 yaş altındaki kırıkların \%42'si erkeklerde, \%27'si ise kızlarda görülmektedir. ${ }^{[4]}$ Erkek çocukların yaralanmalarındaki artış nedeninin, çeşitli spor aletleri kullanmak ve bisiklet sürmek gibi, erkek çocuklar tarafindan daha fazla uygulanan aktiviteler olduğu düşünülmektedir. ${ }^{[5]}$

\section{TRAVMA}

Çocuklarda kırık nedenlerinin başında basit düşme yer alır. Schalamon ve ark.'nın çalışmalarına göre, çocuklarda kırıkların \%41,9'u, Rennie ve ark.'nın çalışmalarına göre ise \%57'si basit düşme sonrası oluşmaktadır. ${ }^{[6]} \mathrm{Ev}$, okul ortamında, oyun ve eğlence faaliyetlerinde ve trafikteki kazalara bağlı travmalarda da çocuk kırıkları ile sıklıkla karşılaşııır. Kaza ile oluşan bu yaralanmalar çeşitli önlemler ile azaltılabilir. Çocuk kırıklarının bir diğer nedeni de travmalı çocuklarda her zaman göz önünde bulundurulması gereken "çocuk istismarı" durumudur. Uzun kemik cisim kırıkları, yanıklar, vücutta çeşitli yerlerde farklı evrelerdeki ekimozlar ve sağlık kurumlarına geç başvurulması gibi çocuk istismarını düşündürecek durumlarda, ilgili merkezlere yapılacak bildirimler büyük önem taşır. Travma öyküsü olmayan, küçük travmalar ile oluşan, kırık öncesi de ilgili ekstremitede ağrı öyküsü bulunan hastalarda ise, patolojik kırıklar göz önünde bulundurulmalıdır.

- Illetişim adresi: Dr. Osman Nuri Özyalvaç, Metin Sabancı Baltalimanı Kemik Hastalıkları Eğitim ve Araştırma Hastanesi, Rumeli Hisarı Cd. No:62, 34470, Baltalimanı, İstanbul Tel: 0505 - 9871799 e-posta: nozyalvac@yahoo.com

- Geliş tarihi: 2 Şubat 2019 Kabul tarihi: 2 Şubat 2019 
Çocuklarda patolojik kırıklar, çeşitli metabolik hastalıklar, tümör ve enfeksiyon gibi durumlarda görülebilmektedir. ${ }^{[7]}$

\section{ANATOMIK YERLEŞIM}

Çocuklarda en sık görülen kırık radius distal uç kırığıdır. Bu oran farklı çalışmalarda \%15,3-30,4 arasında değişmektedir. ${ }^{[1,3,8]}$ Radius distal uç kırığının sık görülmesinin nedeni, araştırmacılar tarafından, hızlı büyüme döneminde kemik metafizinde gelişen geçici bir osteopeni olarak düşünülmüştür. ${ }^{[9,10]}$ Radius distal uç kırıklarından sonra çocuklarda en sık görülen kırıklar, sırası ile; distal humerus, klavikula, tibia ve femur kırıklarıdır. ${ }^{[5]}$

\section{SOSYAL ETMENLER}

Çocuk kırıklarının insidansı yaşadıkları coğrafi ve sosyokültürel ortamlara göre de farklılıklar göstermektedir. Laffoy ve Wesfelt'in araştırmalarına göre, düşük sosyokültürel çevrede yaşayan çocuklar yüksek sosyokültürel çevrede yaşayan çocuklara göre daha fazla travmaya maruz kalmaktadırlar. ${ }^{[11]}$ Benzer şekilde, şehirlerde yüksek apartmanlarda yaşayan çocuklar ile kırsal alanlarda yaşayan çocuklar arasında da kırık insidansları açısından farklılıklar mevcuttur. ${ }^{[5]}$ İsveç'te yapılan bir çalışmaya göre, bozuk aile yapısı ve alkol bağımlı aile bireylerinin varlığı, çocuk kırıkları açısından, çocuğun yaşadığı evin fiziksel yapısından daha önemli bir risk faktörüdür. ${ }^{[4]}$

\section{MEVSIMSEL ETMENLER}

Çocuk kırıklarının insidansı mevsimsel farklılıklardan önemli ölçüde etkilenmektedir. Okulların tatil olduğu güneşli ve sıcak mevsimlerde çocuklarda açık alan aktiviteleri artmakta ve daha fazla çocuk travmaları ve kırıkları ile karşılaşılmaktadır. ${ }^{[12]}$ Masterson ve ark.'nın çalışmalarına göre, yaz aylarında görülen kırık olguları kış aylarına göre 2,5 kat artmaktadır. ${ }^{[13]}$ Aynı zamanda, kırık insidansının gün içerisinde özellikle öğleden sonra saat iki ile üç arasında zirve yaptığı, kırıkların güneşli saatlerde arttığı, yağmurlu saatlerde ise azaldığı gösterilmiştir. ${ }^{[13,14]}$

\section{TEDAVi}

Çocuklarda kırık görülme sıklığı bu kadar fazla olmasına rağmen, çocuk kemiğinin kendine has özellikleri nedeni ile, yetişkin kırıklarına göre komplikasyon oranı düşüktür ve kaynama süresi daha kısadır. Çocuk iskeletini yetişkin iskeletinden ayıran özellikler, kalın bir periosta sahip olması ve büyüme potansiyelini sağlayan fizlerin bulunmasıdır. Bu sayede, çocuk kırıklarının iyileşme süreleri kısa ve remodelasyon potansiyelleri fazladır. Teknolojideki gelişme ile minimal invaziv ve perkutan cerrahi tekniklerin artması, ailelerin bilinçlenmesi ve beklentilerinin artması, erken mobilizasyon ve hastanede yatış süresinin azaltılması gibi nedenlerle, zaman zaman cerrahi tedavi seçenekleri tartışma konusu olsa da; çocuk kemiğinin yukarıda bahsedilen özellikleri sayesinde, çocuk kırıklarının büyük çoğunluğu, başta kapalı redüksiyon ve alçılama olmak üzere, halen konservatif tedavi yöntemleri ile tedavi edilmektedir. Schalamon ve ark.'nın çalışmalarına göre, çocuk kırıklarının \%22,3'üne, Kalenderer ve ark.'nın çalışmalarına göre ise \%16'sına cerrahi tedavi uygulanmıştır. ${ }^{[3,8]}$ Cerrahi tedavi gerektiren kırıkların büyük çoğunluğunu distal humerus kırıkları oluşturmaktadır.

\section{TÜRKIYE'DEKI DURUM}

Ülkemizde çocuk kırıklarının etiyolojisi ve epidemiyolojisi ile ilgili sınırlı sayıda çalışma bulunmaktadır. Mevcut çalışmalar ise genellikle yerel sonuçları içermektedir. Tarğal ve ark., 2015 yılında 16 yaş altı 1878 kırık hastası üzerinde yaptıkları araştırmada, yaralanmaların en çok evde düşme sonrası olduğu, radius distal uç kırığının tüm kırıkların \%23,5'ini oluşturduğu, $\% 6,2$ oranında cerrahi tedavi gerektiği ve kırıkların sıklıkla yaz aylarında olduğu sonucuna varmışlardır. ${ }^{[15]} \mathbf{i}_{c ̧}$ Anadolu Bölgesi'nde yapılan, 16 yaş altı 528 kırık hastasını içeren bir başka çalışmada, kırıkların genelde yaz mevsiminde ve basit düşme sonucu olduğu ve çoğunluğun konservatif yöntemlerle tedavi edildiği gösterilmektedir. ${ }^{[16]}$ Bombacı ve ark. da İstanbul'da yaptıkları çalışmalarında, okul döneminin başı (7 yaş) ve ergenlik çağının başında (12 yaş) çocuk yaralanmalarında artış gözlemlemişlerdir. ${ }^{[17]}$

\section{ÇIKARIMLAR}

Sonuç olarak; çocuk kırıkları daha çok yaz aylarında ve erkek çocuklarda görülmektedir. Ülkemizin iklim özellikleri de, sıcak havalarda ve tatil dönemlerinde çocukların dışarda geçirdikleri vakitlerin artmasına ve kırık oluşumuna zemin hazırlamaktadır. Çocuk yaralanmalarının önüne geçmek için ev, okul ve oyun alanları gibi çocukların yoğun olarak vakit geçirdiği ortamlarda gerekli önlemlerin alınması, trafik kazalarının önüne geçebilmek adına eğitim ve cezai yaptırımların arttırılması, başta hekimler olmak üzere tüm sağlık personelinin çocuk istismarı konusunda bilgilendirilmesi gerekmektedir.

\section{KAYNAKLAR}

1. Hedström EM, Svensson $O$, Bergström $U$, Michno $P$. Epidemiology of fractures in children and adolescents. Acta Orthop Scand 2010;81(1):148-53. Crossref 
2. Cooper C, Dennison EM, Leufkens HGM, Bishop N, vanStaa TP. Epidemiology of childhood fractures in Britain: a study using the general practice research database. J Bone Miner Res 2004;19(12):1976-81. Crossref

3. Schalamon J, Dampf S, Singer G, Ainoedhofer H, Petnehazy T, Hoellwarth ME, Saxena AK. Evaluation of fractures in children and adolescents in a level 1 trauma center in Austria. J Trauma 2011;71(2):E19-E25. Crossref

4. Landin LA. Fracture patterns in children: analysis of 8 , 682 fractures with special reference to incidence, etiology and secular changes. Acta Orthop Scand (Suppl 202) 1983;54(sup202):3-109. Crossref

5. Cheng JC, Shen WY. Limb fracture pattern in different pediatric age groups: a study of 3,350 children. J Orthop Trauma 1993;7(1):15-22. Crossref

6. Rennie L, Court-Brown CM, Mok JYO, Beattie TF. The epidemiology of fractures in children. Injury 2007;38(8):91322. Crossref

7. De Mattos CB, Binitie O, Dormans JP. Pathological fractures in children. Bone Joint Res 2012;1(10):272-80. Crossref

8. Kalenderer Ö, Gürcü T, Reisoğlu A, Ağuş H. Acil servise kırık nedeniyle başvuran çocuk hastalarda kırıkların sıklık ve dağılımı. Acta Orthop Traumatol Turc 2006;40(5):384-7.

9. Bailey DA, Wedge JH, McCulloch RG, Martin AD, Bernhardson SC. Epidemiology of fractures of the distal end of the radius in children as associated with growth. J Bone Joint Surg Am 1989;71(8):1225-31. Crossref
10. Hagino $\mathrm{H}$, Yamamoto $\mathrm{K}$, Teshima R, Kishimoto $\mathrm{H}$, Nakamura $\mathrm{T}$. Fracture incidence and bone mineral density of the distal radius in Japanese children. Arch Orthop Trauma Surg 1990;109(5):262-4. Crossref

11. Laffoy M. Childhood accidents at home. Ir Med J 1997;90(1):26-7.

12. Tiderius CJ, Landin L, Diippe $H$. Decreasing incidence of fractures in children: an epidemiological analysis of 1,673 fractures in Malmo, Sweden, 1993-1994. Acta Orthop Scand 1999;70(6):622-6. Crossref

13. Masterson E, Borton D, O'Brien T. Victims of our climates. Injury 1993;24(4):247-8. Crossref

14. Nathorst Westfelt JA. Environmental factors in childhood accidents. A prospective study in Göteborg, Sweden. Acta Paediatr Scand Suppl 1982;291:1-75.

15. Tarğal A, Haberal B, Şeşen H, Demirkale i, Ateş A, Altay M. Pediatrik Yaş Grubunda Acil Serviste 1 Yılda Tespit Edilen Ekstremite Kırıklarının Etiyoloji ve Epidemiyolojisi: 1878 Çocuk ile Çalışma. Akademik Araştırma Tıp Derg 2018;2(2):44-8.

16. Zümrüt M. Epidemiological Evaluation of Fractures in Children Presenting to the Emergency Service. Kocatepe Med J 2014;15(2):142-6.

17. Bombaci H, Ulkü K, Adiyeke L, Kara S, Görgeç M. Childhood injuries, their etiologies, and preventive measures. Acta Orthop Traumatol Turc 2008;42(3):166-73. Crossref 